\title{
Healthy Religiosity
}

Joe Chelladurai

\section{Overview}

Research on religion has been increasing steadily over the recent decades. There are several academic journals and international and national organizations interested in the social scientific scope of religion. It is well known that religion has been a powerful influence for good and bad, and debates of this nature are likely to continue. As a bystander to such conversations, I am drawn to think as what about religion that has such a potent influence. Relatedly I wonder in what ways and in what conditions can religion be a positive and helpful aspect of people's lives. While previous research has focused on the correlates and the influence of religion on health outcomes, I aim to examine what type of religious observance is related with such outcomes. Questions like, what religious beliefs are facilitative? which aspects of religion can be beneficial to people?, and relatedly, how does one practice religion in a healthy way? Finding some answers can have potential implications for religious and non-religious people, clergy, and for people who have high religious priorities.

\section{Aspects of Healthy Religiosity}

1. Embracing Benevolent Ideologies

2. Exercising Agency

3. Accommodating Worldviews

4. Sanctifying Relationships

5. Coping with Challenges

6. Finding Meaning

7. Journeying and Questing

8. Striving without Unnecessary Struggle

9. Resolving and Avoiding Obsessions

10. Overcoming Guilt

11. Developing Compassion

12. Being Prosocial

\footnotetext{
*to be updated soon
} 